\title{
Concept of Artifact-Event Description of Information System
}

\author{
Levykin Viktor $^{1}$ \\ Yevlanov Maksym² \\ Neumyvakina Olga ${ }^{3}$ \\ Petrichenko Oleksandr ${ }^{4}$
}

${ }^{1}$ Kharkiv National University of Radio Electronics, 14 Nauky Ave, KharkivUA-61166, Ukraine, viktor.levykin@nure.ua

${ }^{2}$ Kharkiv National University of Radio Electronics, 14 Nauky Ave, KharkivUA-61166, Ukraine, maksym.ievlanov@nure.ua

${ }^{3}$ Kharkiv National University of Radio Electronics, 14 Nauky Ave, KharkivUA-61166, Ukraine, olga.neumyvakina@nure.ua

${ }^{4}$ Kharkiv National University of Radio Electronics, 14 Nauky Ave, KharkivUA-61166, Ukraine, oleksandr.petrichenko@nure.ua

\begin{abstract}
The idea of artifact-event description of a web-based IS during its operation is formulated. Definitions of the concepts of "artifact" and "event" are proposed. Based on these definitions, the concept of an artifact-event description of IS during its operation was developed as a set of basic provisions on the basis of which models of web-based IS will be developed. The developed concept was the basis for a formalized description of web-based IS models set. The main dimensions, on the basis of which the formalization of the descriptions of the web-based IS and its elements, are allocated. A formalized description of the web-based IS models set and its elements is proposed, the main subsets of models forming this set are considered.
\end{abstract}

Keywords: information system, IT-service, artifact, event, model, commutative diagram.

\section{INTRODUCTION AND PROBLEM STATEMENT}

Modern ideas about the life cycle of information system (IS) allow us to present the totality of the work of any particular IT company in the creation, implementation, maintenance and development of IS as a set of special cases of individual standard processes that are performed sequentially or parallel to each other. The connection between such processes is carried out through many artifacts, which are the results (outputs) of one process and at the same time the necessary information to start another process (inputs). However, it remains unclear today: is it possible to unify the presentation of such artifacts for IS for various purposes. Positive solution to this issue will significantly improve the efficiency and quality of management of IS life cycle processes by reasonably transferring the most successful management models, methods and practices identified on the basis of experience. Therefore, studies on the development of unified formal descriptions of IS and their elements are relevant not only from a theoretical, but also from a practical point of view.

Currently, two main ways of describing IS are used architectural frameworks and visual modeling languages. However, both methods involve the conversion of one IS description into another based on a set of general or particular knowledge and rules. Analysis of modern systems description languages (for example, SysML [1]) and architectural frameworks (for example, TOGAF [2] or RM-ODP [3]) suggests that these rules can be implemented as follows:

- Particular rules for transforming one set of elements of visual models into another;
- Set of general rules establishing the architectural semantics of different languages;

- Set of general models and rules embodied in the form of a base or storage of IS artifacts.

Therefore, it is necessary to solve the problem of developing the concept of a formal description of IS and its elements, on the basis of which it will be possible to form similar sets of particular and general rules.

\section{PROBLEM SOLUTION AND RESULTS}

Term "IS artifact" we will characterize that determinations:

- Description of a separate element of IS at different stages of its life cycle;

- Description of IS as a whole as an element of a larger system.

An event that occurs during the operation of an IS or its element we will be characterize as separate action from the set of permissible actions performed on one, several, or all artifacts of the IS and elements of this artifacts and leading to a change in the state of these artifacts.

Use of events to describe the behavior of IS allows us to formulate the concept of an artifact-event description of IS during its operation as a set of the following provisions:

- Any IS can be represented as a set of separate artifacts that establish the set of acceptable states of the IS and its elements, and the set of events that transfer these artifacts from one state to another;

- Any description of any IS artifact and event is an element of the universum, which includes both known and unknown to the Supplier, Consumer, or both of them IP artifacts and events, as well as methods for generating these artifacts and events;

- Any description of any IS artifact and event is considered as the initial variety of representations of the IS element at different stages of its life cycle at the level of data, information and knowledge;

- Any description of any IS artifact or event should be based on a process approach that defines the minimum process attribute model of IS element at different stages of its life cycle;

- Management of any IS artifact or event should be based on an approach based on the principle of gradually converting the set of initial attribute values describing this artifact or this event into the set of desired values of the same attributes.

In accordance with the service approach to the description of IS described in [4], it is proposed to use the following presentation levels of the operating IS: 
- Level of managed objects and / or processes;

- System-wide level;

- IT accommodation (function) level;

- IT service level.

The concept of an artifact-event description of IS and its elements allows to distinguish the following levels of a formal description of an exploited IS:

- IS meta-metamodels level (a subset of artifact and event models);

- Level of IS metamodels (a subset of models of individual elements of IS and IS as a whole, based on an artifact-event description of IS);

- Level of IS models (a subset of the models of a particular operating IS and its individual elements formed on the basis of IS metamodels).

The need for a formal description at the same time according to the two dimensions highlighted above leads to a conceptual description of models set of operated web-based IS in the form of a two-dimensional matrix

$$
M_{w I S}=\left[\begin{array}{cccc}
M_{w I S}^{31} & M_{w I S}^{32} & M_{w I S}^{33} & M_{w I S}^{34} \\
M_{w I S}^{21} & M_{w I S}^{22} & M_{w I S}^{23} & M_{w I S}^{24} \\
M_{w I S}^{11} & M_{w I S}^{12} & M_{w I S}^{13} & M_{w I S}^{14}
\end{array}\right],
$$

where $M_{w I S}$ - is many models of exploited web-based IS; $M_{w I S}^{31}$ - is subset of artifact models that describe an abstract web-based IS as a single integrated IT product, and events that occur with these artifacts; $M_{w I S}^{32}$ - is subset of artifact models describing an abstract web-based IS as a system consisting of personnel and complex automation, and events occurring with these artifacts; $M_{w I S}^{33}-$ is subset of artifact models that describe an abstract web-based IS as a system of separate IT accommodation (function), and events that occur with these artifacts; $M_{w I S}^{34}$ - is subset of artifact models that describe an abstract web-based IS as a system of separate IT services, and events that occur with these artifacts; $M_{w I S}^{21}-$ is subset of models describing an abstract web-based IS as a single integrated IT product in terms of an artifact-event description; $M_{w I S}^{22}$ - is subset of models describing an abstract web-based IS as a system consisting of personnel and complex automation in terms of an artifact-event description; $M_{w I S}^{23}$ - is subset of models that describe an abstract web-based IS as a system of separate IT accommodation (function) in terms of an artifactevent description; $M_{w I S}^{24}$ - is subset of models that describe an abstract web-based IS as a system of separate IT services in terms of an artifact-event description; $M_{w I S}^{11}-$ is subset of models describing a particular exploited web-based IS as a single integrated IT product in accordance with metamodels $M_{w I S}^{21} ; M_{w I S}^{12}-$ is subset of models describing an abstract web-based IS as a system consisting of personnel and complex automation in accordance with metamodels $M_{w I S}^{22}$; $M_{w I S}^{13}$ - is subset of models that describe an abstract webbased IS as a system of separate IT accommodation (function) in accordance with metamodels $M_{w I S}^{23} ; M_{w I S}^{14}$ is subset of models that describe an abstract web-based IS as a system of separate IT services in accordance with metamodels $M_{w I S}^{24}$.

For matrix (1), the following condition is mandatory

$$
\begin{gathered}
\forall i=1 \ldots 4, j=1 \ldots 3, a=1 \ldots 4, b=1 \ldots 3, b \neq j \\
\exists M_{w I S}^{i j} \cap M_{w I S}^{a b}=\varnothing .
\end{gathered}
$$

Depending on the approach to describing a web-based IS adopted at the stages of its creation and implementation, mappings forming commutative diagrams, can be defined on set (1). Example of this diagram is given below:

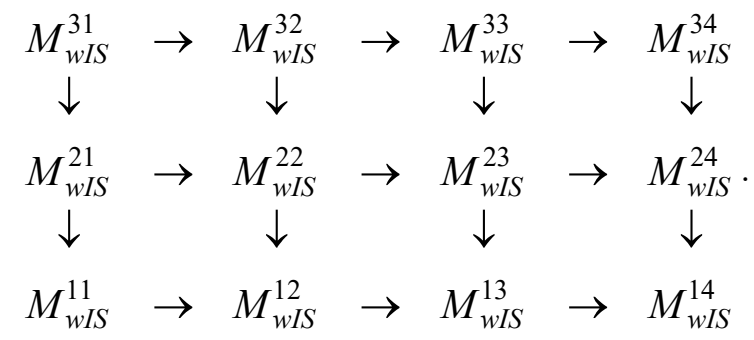

\section{CONCLUSIONS}

The proposed models set allows you to formally describe all the possible tasks that arise during the operation management of a web-based IS.

Given the developed formalized description of models set (1), it becomes possible to develop a model of an artifact, an elementary-single and scenario-single event. It is these models that are proposed to be considered as the main elements of a subset of artifact models that describe an abstract web-based IS as a system of separate IT services and events that occur with these artifacts. Further, it is planned to develop the transformation of these models into a subset of models that describe an abstract web-based IS as a system of separate IT services in terms of an artifact-event description, using the model IT-service model built using the Model-Control-View framework as an example.

\section{REFERENCES}

[1] F. Oquendo, J.C. Leite and T. Batista. Doftware Architecture in Action Designing and Executing Architectural Models with SysADL grounded on the OMG SysML Standard. Undergraduate Topics in Computer Science. Springer. 2016. DOI: https//doi.org/10.1007/978-3-319-443393 .

[2] "The Open Group Architecture Framework (TOGAF) - Core Concepts". Available at: http://www.togaf.org/togaf9/chap02.html\#tag_03_01.

[3] ISO/IEC 10746-2-1996. Information Technology - Open Distributed Processing - Reference Model: Foundation. ISO/IEC Copyright Office, 1996.

[4] V.M. Levykin, M.V. Yevlanov, and M.A Kernosov. Pattern planning of requirements to the informative systems: design and application. Kharkov, Ukraine: Kompaniya «Smit LTD», 2014 (In Russian). 